\title{
2 The Use of Visibility in Contentious Events in Northern Ireland
}

\author{
Katy Hayward and Milena Komarova
}

\begin{abstract}
Territorial space in Northern Ireland is often associated with certain communal and political identities. This is vividly demonstrated by traditional parades in local areas. Some parades become contentious because they pass through localities associated with very different communities. Often, contentious parades are met with protests, which can become violent. Based on ethnographic fieldwork on the contentious Protestant Orange Order parade through Ardoyne in North Belfast, we interpret contentious events not just in the usual terms of territorial struggles but as a quest for visibility. A focus on visibility as a field of social action, through which territories are established and contested, illuminates better the social relationships at work and the effects of their contestation at their nexus.
\end{abstract}

Keywords: visibility, parades, protest, conflict, Belfast

\section{Introduction: The Twelfth July in Ardoyne}

On the morning of Wednesday, 12 July 2017, there was a Protestant Orange Order parade from the Orange Lodge in Ballysillan in North Belfast. As it has done each 'Twelfth' for generations, the parade's route came down the Crumlin Road through Ardoyne (with its predominantly Catholic population) into Woodvale (with a predominantly Protestant population), before continuing on into Belfast city centre. Strict conditions were enforced on the parade as a result of the decision of the Parades Commission - the agency tasked with determining the rules for the conduct of parades,

McGarry, A., I. Erhart, H. Eslen-Ziya, O.Jenzen, U. Korkut (eds), The Aesthetics of Global Protest: Visual Culture and Communication. Amsterdam: Amsterdam University Press, 2020 DOI 10.5117/9789463724913_CHO2 
particularly those (such as this one) likely to be contentious. ${ }^{1}$ The Police Service of Northern Ireland (PSNI) enforced these conditions in a carefully light-touch way. Whilst a few officers in summer uniform of peaked cap and shirtsleeves interacted face to face with the leaders of the parade and its supporters, dozens of officers waited in police Land Rovers in streets adjacent to the Crumlin Road with riot gear at the ready.

The progress of the parade down the Crumlin Road was closely followed by a police helicopter overhead, by several journalists (including a TV crew from Belgium), and a sizeable group of supporters by phone who were waiting at the roundabout interconnecting Woodvale and Ardoyne. However, for the first time in years, something was missing: there were no protestors to meet the procession as passed through Ardoyne. Even more noticeable was the absence of violence in the area that evening - another 'tradition' that has evolved in connection with the contentious nature of the parade. Indeed, the Twelfth parade through Ardoyne has long been associated with riotous and violent behaviour. In 2011 - the year we first started observing the passing of the Twelfth feeder parade of three Orange Order lodges ${ }^{2}$ through Ardoyne - the news reported outbreaks of sectarian rioting and violence against the PSNI to an extent not seen for at least a decade (BBC 2011).

This chapter is based on research that originated with the Economic and Social Research Council (ESRC)-funded 'Conflict in Cities and the Contested State' project and has produced eight years of unbroken ethnographic fieldwork on contentious annual events in Belfast. It draws on data that includes field observations from different perspectives and locations: from alongside a marching band, to pressed up against a police line, to standing with protestors, to observing (via helicopter feed) from the distance of a PSNI Gold Command Room. Our methods included qualitative primary research based on ethnographic observation and interviews, including 'walking interviews' with a range of participants, involving local residents, Orange men, local politicians, police officers, and community workers. We have also conducted extensive desk research including analysis of media coverage of the events, analysis of official documents (particularly Parades Commission determinations) and photographic and video archives of the events in

1 The Parades Commission of Northern Ireland is an independent public body established in 1997 - after a period of growing tension and violence around contentious parades. Under the Public Processions (Northern Ireland) Act 1998, the commission is tasked with facilitating mediation between disputing parties regarding public processions and issuing determinations in respect of proposed public processions and protest meetings. Its determinations and, indeed, its legitimacy have been frequently challenged by both sides (Walsh 2015).

2 LOL no. 1932 Ligoniel True Blues, the Ballysillan LOL 1891 and the Earl of Erne LOL no. 647. 
question. This longitudinal qualitative methodology has been integral to the content of our findings and particularly to our ability to reframe our understanding of the significance and management of contentious events in Northern Ireland.

This chapter explores the thesis that understanding conflict around contentious events rests not only on police tactics, territorial containment or political compromise but also on appreciating the quest for visibility among actors involved. Visibility may be understood as a field of social action through which territoriality is established and relationships of power are contested and maintained. We see all actors in a contentious event such as an Orange parade through Ardoyne engaging in their own efforts to be 'visible' - not just to their own group but also to each other and to a wider, external audience. Drawing on Brighenti's (2010a, 2010b, 2010c) insights, we illustrate three forms of public visibility at work in this context: Spectacle, Recognition, and Control. A more comprehensive encounter with and accounts of types of visibility at work during a contested event will assist us to better comprehend the most effective means of defusing the friction around the visual regimes of protest.

\section{Contentious Parades}

The parading tradition in Northern Ireland has a long history (Bryan 200o). Parading on Twelfth July commemorates the 1690 victory of the Dutch King William of Orange at the Battle of the Boyne over the English (Catholic) King James II. It is the most significant commemoration in the annual calendar of Protestant unionists in Northern Ireland. ${ }^{3}$ Whilst predominantly associated with the Protestant community, parading has also been part of some Catholic traditions too, notably the Ancient Order of Hibernians and some republican groupings (Browne 2016). The parading tradition in Northern Ireland is a classic enactment of commemoration. Be it republican commemorations of the 1916 Easter Rising or the Apprentice Boys' commemoration of the siege of Derry, the parade is part of a ritual of collective memory. As such it can be understood as one means of solidarity formation, creating a sense of unity and collective consciousness through the shared performance of a ritual (Durkheim 2001).

3 According to the 2011 census, $48 \%$ of the population in Northern Ireland come from a Protestant background. Around $84 \%$ of them, according to the Northern Ireland Life and Times Survey of 2017, hold 'unionist' political aspirations, which is to say that they want Northern Ireland to remain part of the United Kingdom. This is in distinction from the predominantly Catholic nationalists in Northern Ireland, who would like to see Northern Ireland becoming part of a united Ireland. 
However, the use of collective memory formation and ritual also contains a particularly sharp political edge in the context of a divided society such as Northern Ireland. Political behaviour and belief are central to the use and construction of identity in such a performance of collective memory and solidarity (Ross 2007). This is why, as Jarman (1997) explains, the use of symbols and iconography in parades in Northern Ireland is not just intended to assert a particular form of cultural identity, but also to give a tangibility to deeply held, antagonistic political views. As such, parades are an integral form of sustaining mutual antagonism as well as entrenching cultural difference. This is particularly true when they pass through communities of a very different cultural and political tradition. Commemoration (and contestation in the form of protests at parades) strengthens group experience in relation to place, but it also opens it up to challenges, which are based on and exercised through local space. For such reasons, contention around parades appears to be a microcosm of wider political and communal tensions in Northern Ireland. Violence and disorder at such events are seen as significant indicators of risk for the wider political compromise in Northern Ireland, especially if the forces of law and order appear to be biased or unbalanced in their management of the event.

The annual occurrence of contentious parades and protests in Northern Ireland are typically explained as an expression/manifestation of the relationship between communal identity and territory, i.e. a manifestation of social territoriality. Therefore, they are seen as a struggle over territory (Cohen 2007). Although where and when parades and protests are performed is very important to their understanding, we suggest that it is not place itself that is of most importance in such events, but rather the way in which the practice and performance of parades and protests in particular spots produces certain visibilities for different participants and for the general public. This is because visibility, as argued by Brighenti (2010c), is itself central to the social production of space, to claiming and contesting territory, and to the broader production of the public sphere (and the associated relationships of power). Drawing on Brighenti's work, we see that events are made contentious by the type of visibility that participants in a contentious event are seeking and are given at any particular point.

This is a particularly useful lens through which to understand how contention increases and is ameliorated. The complexity of the matter is in part because there are several groups of persons that contribute to the performance and management of the event itself. This includes the marchers, the supporters of the parade, the protestors, the agitators, the observers (such as journalists), and, finally, the police. A better understanding of the 
type of visibility at work during a contentious event relating to the position and action of these groups will assist us to better appreciate the social effects of performances in such events. Our research has shown that the participants are astutely aware of and do consciously use various techniques and devices of visibility to communicate and interact with various audiences while claiming, contesting or resisting (ascribed) subject positions. As such, visibility is not simply a tool through which to (re)claim territory, but it could also be at the very centre of contestation itself, that is, it is what is being fought over. The necessity for visibility itself, in other words, can be understood as one of the reasons for the intractability of local contestation.

\section{Visibility}

In the introduction to this volume McGarry et al. describe protest as a performative operation of democratic power through which the democratic public 'demands recognition, embodies visibility, articulates a political voice, and communicates ideas/demands'. As such, protest is a performative act of public communication that aims to contest the existing power relations and 'the rules of the game' that may be dictated by those in positions of authority. More broadly speaking, as Gambetti affirms, '[T]he public sphere [is] a space of appearances where conflicts, identities, differences, communalities and power structures are compellingly revealed to a heterogeneous multitude [...]: a public is constituted performatively as the addressee of discourses and practices that brings [sic] it into being' [emphasis added] (2004: 2). Not only are human relations of inter-visibility essential to publicness, as the above suggests, but also publicness itself is innately performative. In order to communicate, publics need to make themselves and their claims visible and as such - recognizable - often through literal physical and spatial performances. Parkinson states: 'This is more than an empirical point about how people in the real world communicate; it is a theoretical point about the conditions of democratic communication' (2012:35). The public sphere as such is a space of communication through visibility.

Visibility itself, as noted by Brighenti (2010c: 186), is a complex social field of meaning, action and communication, which helps to separate 'the perceptible or noticeable from the imperceptible or unnoticeable'. It thus encompasses many other forms of 'managing attention and determining the significance of events and subjects' (Brighenti 2010a: $5^{2}$ ). As such, performative activities such as parading or protesting seek to draw attention away from alternative narratives and identities, rendering them less significant. 
In a similar manner, Ryan (this volume) sees visibility as a 'framing' device and a resource through which social movement activists and leaders seek to draw support for their actions and recognition of their identities. Even if this is achieved just for a brief and temporary period, this may be considered a symbolic and worthwhile 'victory' for a community that considers itself to be under threat or in conflict.

One level through which visibility operates is 'socio-technical', i.e. involving space, materiality and technology (Brighenti 2010c). Commonplace discussions in architecture, for instance, suggest that the built form shapes perception and cognition and can make spatial order appear 'natural' or 'unchangeable' through both concealing and revealing social relations (Dovey 2005: 291). Physical space, in other words, can work as a visibility device that gives shape to publicness, allowing for certain kinds of social action to 'take place' in certain localities and, as such, makes a crucial difference to the way that power relations work. For example, the extent of proximity is central, as Allen (2003:148) stresses, to the exercise of relationships of authority: 'the more direct the presence, the more intense the impact'. The same holds for coercive relationships, that most visible imprint of power, where the threat of force lasts only for as long as people feel constrained by its possibility.

Yet, space is not an inert container of social action. It is itself the outcome of social relations. As such, another level at which the field of visibility operates is the 'bio-political' (Brighenti 2010c), i.e. that of social practices, actions and interactions, down to the micro-level of the positioning of bodies and gestures. In this respect Brighenti (2010c: 123) notes that:

[P]ublic space on the ground is constantly made by acts of territorialisation, which are themselves processes made up of different thresholds and dynamics of visibility, carving the environment through acts of boundary-drawing.

Visibility as such is a way of 'prolonging' the territorial social relations (including power relations) inscribed in physical space by managing perception and attention. In short, Brighenti (2010a: 52 ) concludes, 'visibility lies at the intersection of the two domains of aesthetics (relations of perception) and politics (relations of power)'.

\section{Regimes of Visibility}

As a field of social action, visibility is strategic and relational: it is manipulated by social actors for different end goals, while its effects depend on the 
means and conditions in which it is generated. The effects themselves can be asymmetrical and these asymmetries, as Brighenti (2010a) suggests, are organized 'around regimes of visibility'. The author discusses three regimes of visibility - 'recognition', 'control' and 'spectacle' - taking care to stress that they are not mutually exclusive.

Visibility as 'recognition', which we briefly discussed above, is perhaps most commonly encountered in the fabric of everyday life. Looking at each other is where we constitute ourselves as 'subjects' (Brighenti 2010c). As Goffman (2005) further notes, acknowledging the visibility of others legitimises them as participants in a social situation. In the case of the parades and protests which we discuss in this chapter, this form of visibility captures the actively constructed 'identity work at play' which participants engage in. Here, 'the public square acts as a theatre where the individual and collective identities of protestors are performed' and 'ideas of democracy, including specific demands and grievances' are communicated (McGarry et al., this volume). Achieving visibility in the form of recognition is, therefore, not simply about constructing identity but is inherently an act of empowerment, particularly common to the repertoire of social movements (Honneth 1995). As Mirzoeff (this volume) states, the very exchange of glances 'in the non-enclosed encounter' is 'an apprehension of the claim of the other to the right to look'. The quest for visibility as a form of recognition is similarly discussed by Mercea and Levy (this volume) when referring to the pursuit of visibility by activists of Occupy Gezi on Twitter as a 'subaltern tactic' to reverse an asymmetry of power and engage 'into a struggle for recognition and participation'.

By contrast, visibility as social 'control' can be disempowering. Here social actors do not themselves 'struggle for recognition through visibility' but are 'obliged to be visible' (Brighenti 2010c: 49). An example of how visibility as control is constituted can be seen in contemporary surveillance practices. Drawing on Foucault's ideas on power and governmentality (Rose 1999), surveillance wages an impact on and possesses the power to alter one's actions and behaviour by virtue of the very knowledge or the suspicion of being observed. Contemporary professional surveillance knowledge, Brighenti (2010a) adds, intersects with, and even colonizes lay knowledge in the public domain. For example, in our research we have observed how the use of helicopter cameras by police on the day of a contentious event creates visibilities not open or accessible for either protestors or marchers. Policing decisions on the ground are often based on such privileged visibilities, and create a clear consciousness on the part of other participants that pre-existing agreements regarding how a parade and protest will be policed 
can be subject to momentary change. This consciousness often shapes the longer-term relationship that protagonists may have with the police and may infuse it with distrust. Yet neither as recognition nor as control is visibility linearly associated with empowerment or disempowerment. This is because the means through which visibility is produced opens up a range of possibilities for resistance or even unintended counter-effects.

An example of this in our case study is the response of the nationalist party Sinn Féin to the challenge of the Orange parades through Ardoyne. Sinn Féin has strong political support in Ardoyne and would consider itself to be the primary party representing not just nationalists in the local area but nationalists across the island of Ireland. With international focus on contentious events such as the parades through Ardoyne on the Twelfth, Sinn Féin gained a natural opportunity to be visible as well. One Parades Commission representative interviewee described their conundrum in this way:

If they're not on the streets placating, then the raw edge is the police and the people. [...] But if they are there and then they end up with too forward a role, then people will identify them as facilitating a parade or supporting and sponsoring police violence. ${ }^{4}$

There is a careful balance to be struck in visibility. And it is not always clear whether those who are seeking visibility as recognition will manage to avoid being subject to visibility as control. In seeking to become empowered through coordinating protests and through assuming a high-profile role on the day in obvious support for local residents, Sinn Féin could easily become accused of being manipulated and used by the police and even the Orange Order to facilitate the parade. What matters in this instance is the audience. Sinn Féin wants to be seen by the wider audience and the local residents as showing leadership, but it could be seen by critics within its community as demonstrating compliance. Mercea and Levy (this volume) also demonstrate this point clearly when showing that despite its initial success as a pursuit of recognition and participation, the Occupy Gezi movement's visibility on Twitter was soon reversed into becoming 'the basis for reflexive state surveillance'.

The final regime of visibility is perhaps the most straightforward, namely that of the 'spectacle'. The parades and protests that we discuss in this chapter are first and foremost forms of public ritual. At one level, they serve 
as illusory or ideological forms of unity (Durkheim 2001), which intensify collective experience in relation to territory (Koster 2003; Lukes 1975). In another way, crucially, by making a spectacle of themselves as they perform specific roles, social actors become visible to external audiences (Brighenti 2010c). The notion of spectacle is readily embedded in the performance itself. The performers' visibility is an easily understandable social exchange. 'During the spectacle, all gazes are morally authorized to direct themselves at the performer and to fix upon him/her' (Brighenti 2010c: 50). This is not just true of the participants in the parade in the case of our fieldwork. Protestors can also become performers who '[modify] the field of visibilities [...] by offering [themselves] to an audience's gaze' (Brighenti 2010c: 50).

Minute differences in the use of space, gestures, positions, cameras, for example, can all be exploited by performers who are safe in the knowledge that they are being watched, observed, and noticed. The strategic use of any and all of these devices for producing visibility feed into an exercise of power relations and can signal solidarity, resistance, compliance, challenges to authority or lack of legitimacy. As Allen (2008: 1617) suggests, 'the spacing and timing of people's interactions' can be mobilised as resources. Furthermore, as Parkinson (2012: 35) notes, ${ }^{5}$ the demands of our 'mediatized' age are such that political communication is under additional strain to become highly 'spectacular' by nature so that 'issues of staging, lighting, audience access, symbolism and interaction between actors are all important'. Thus, for instance, in our research both the police and local community workers often cited the presence of journalists at contentious events as 'inciting' observers and protestors to engage in conflict or even violent behaviour as a form of performing to external audiences.

\section{Visibility on the Crumlin Road on the Twelfth July}

In order to ascertain the role played by the quest for visibility in the performance of political positions in Ardoyne on Twelfth July, we hereby look at each one of five key groups: marchers/participants in the parade, supporters of the parade, agitators, protestors and police.

\section{Marchers in the parade: Making a spectacle, seeking recognition}

Those marching in the parade can come from several different groups. They may be Orange men or women marching with their Loyal Orange Lodge, or members of a marching band accompanying the lodge on the 


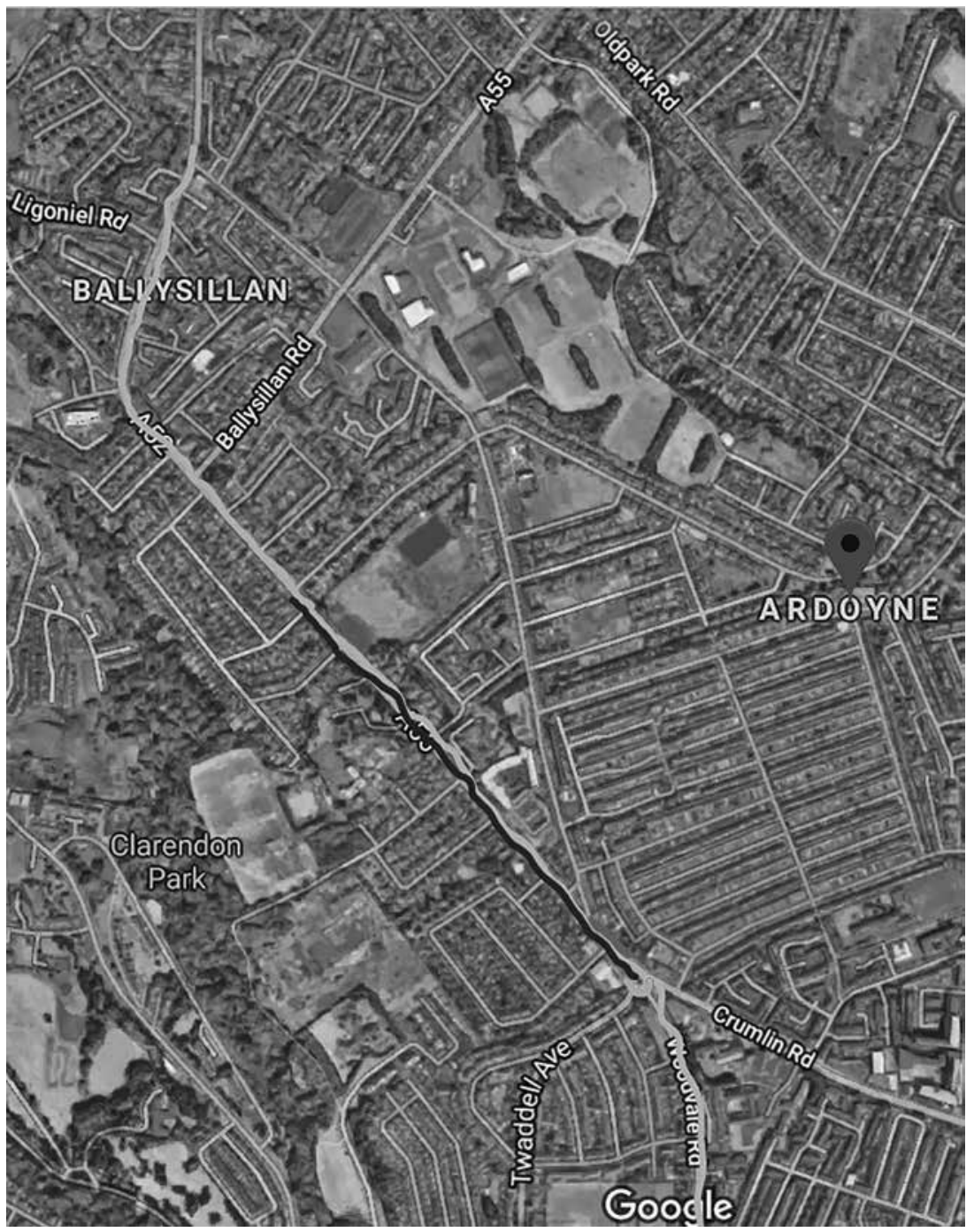

Figure 2.1. Map of Ardoyne from Google Maps. Map data $\bigodot_{2019}$ Google.

parade. Marching bands traditionally include pipes, flutes or drums. This is significant, because the Parades Commission often recommends that a single drum beat be played whilst the parade makes its way through a contested part of the route in order to avoid the risk of sectarian songs being played by a band. A third category of 'marchers' would be supporters who follow the parade down the route, usually up to a certain point. When a lodge submits an application to the Parades Commission for permission to parade down a route on a particular day and time (it must do this for each 
occasion), it is required to predict how many supporters will accompany the parade on the route.

At one level, the regime of visibility for the marchers is very obvious: the parade is a spectacle and their primary role is to perform as part of that spectacle. This is clearly true for the members of the Orange Lodge and, by association, of the bandsmen and women. Yet, something else is also going on in the case of their accompanying marchers: their presence is more than that of the performance of a collective ritual. Beyond creating a spectacle, they are looking for recognition. Our fieldwork suggests that marchers are highly conscious of the contentious nature of the event. This is evident in the conversations that are held (speculating about the size of the protest from the Ardoyne residents, for example); in visible displays that are used (for example, in the bed sheet hung on a fence along the parade route with the words ' $\mathrm{F}$ "ck your talk, we will walk'), including specially prepared T-shirts (one woman wearing a 'No 1 Likes Us We Don't Care' top in 2018); and in the management of the parade itself by stewards in collaboration with the police. The parade always stops at a certain point along the route, at the junction between Hesketh Road (leading directly to the few streets in the Ardoyne area known to have a predominantly Protestant populations) and the Crumlin Road (a major arterial road and the main parading route to the gathering point near the city centre) (fig. 2.1). At this point, the marchers wait - some new supporters join in but many more stop following the parade. From this position - a few hundred metres away from the roundabout where Ardoyne meets Woodvale - marchers can get a sense of the size of the crowd that awaits them: the police presence, the protestors and their supporters waiting in Woodvale (fig. 2.2). The police manage this waiting crowd of around a hundred people (the greater the friction, the greater the crowd) in a low-key way, using requests through band leaders and senior figures in the Orange Lodges present to ensure that marchers comply with the rules set by the Parades Commission. The rules that are relevant in this case would be the need to walk in the middle of the road (not the pavement) and the need for the parade to be within a certain size.

Such rules offer the marchers the possibility of demonstrating acts of resistance - showing that they see the parade as an opportunity for recognition and manifesting the use of cultural symbols (attire, flags), of sound (songs, humming), of space (walking close to the pavement), as well as more obvious acts such as jeering at the protestors or name-calling. Marchers are careful not to violate the rules as a collective act, knowing that it is likely to lead to much greater restrictions on them on the return parade or in future 


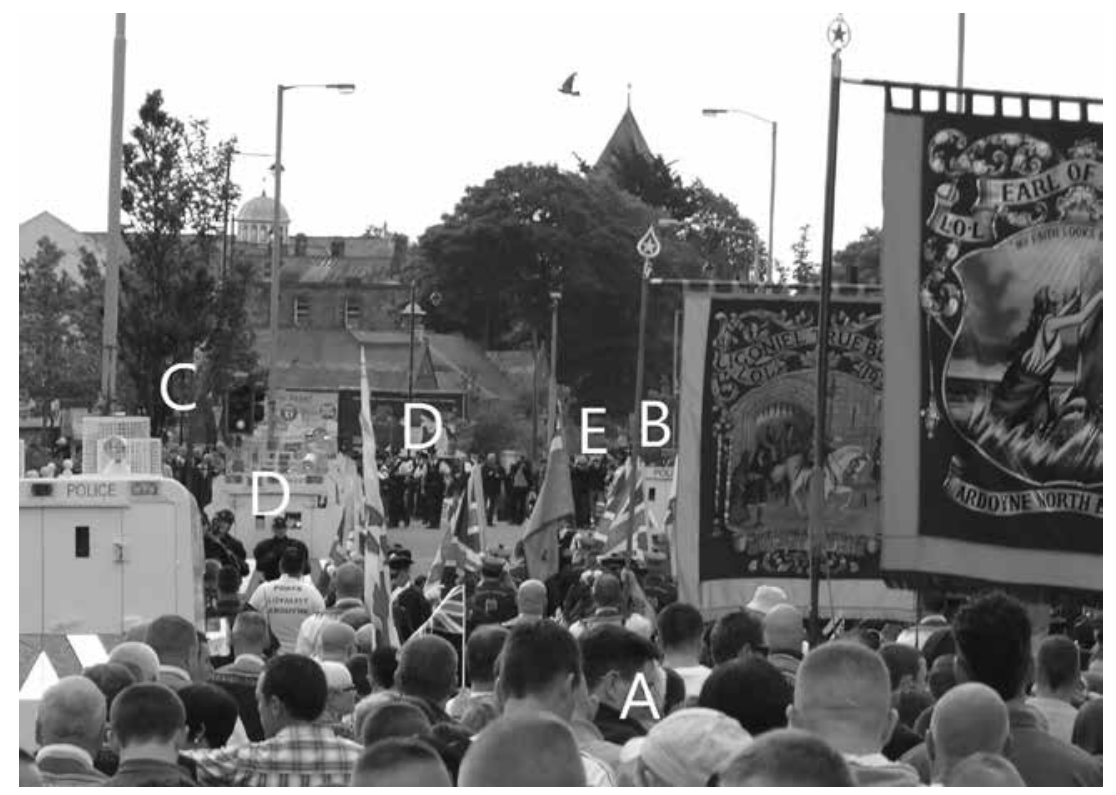

Figure 2.2. The Orange parade through Ardoyne on 12 July 2012, including the marchers (A), their supporters at Twaddell/Woodvale (B), the protestors (C), the police (D) and journalists (E). Image $\odot$ Katy Hayward.

years. In that sense, the 'civilized' morning parade is the clearest space for the manipulation of visibility to seek recognition.

A striking example of this came in 2011 when the parading procession was led, not by an Orange Lodge, but by a group of women holding a large banner with the words: 'Republicanism = Cultural Apartheid'. This was a direct retort to the large banner held by a republican group protesting the march the previous year, with the words 'Re-route sectarian marches'. Other marchers held smaller posters saying 'Respect our culture' whilst protestors' banners demanded: 'Respect our rights'. From an observers' perspective it was clear that marchers and protestors were using their visibility to both communicate with one another and to seek recognition - from each other and from the wider audiences of the highly mediatized event. This is a particular example of the importance of visual culture for political communication. By making their message visible, the paraders and protestors immediately expand the potential reach and impact of their claim.

Furthermore, marchers often seek to make their culture visibly different from those of the nationalist residents of Ardoyne, despite the rulings of the Parades Commission, which are deliberately restrictive with regard to the use of (potentially provocative) symbols. For example, the Parades 
Commission had originally ruled in 2011 that all flags should be furled as the parade passed the protestors in Ardoyne (in order to avoid the flags of loyalist paramilitary groups being displayed). After some harsh criticism from unionist Members of the Legislative Assembly (MLAs), the commission amended its determination to allow the union flag (as the national flag of the United Kingdom) to be unfurled. This was seen as an important concession, not least because nationalist residents in Ardoyne had hung the Irish tricolour (the national flag of the Republic of Ireland) from lampposts along the contested part of the parade route as an act of defiance. The marchers now had a means of direct riposte and they not only carried the Union Jack - the UK flag (sometimes as a shawl), but also wore the colours of the Union Jack (red, white and blue) in their clothing. A few individuals proudly displayed tattoos of the Union Jack on their arms and calves. Individuals' inventiveness when it comes to seeking recognition for their cultural identity is very evident on Twelfth July.

\section{Supporters of the parade: Seeking to bolster the marchers' quest for recognition}

The power of the spectacle of the parade is fuelled, of course, by the fact that it is witnessed. From early morning on the Twelfth July, roads and streets across Northern Ireland are lined with chairs and mini picnic tables as people secure their places on the pavement to get a good view of the parades. Busy highways are turned into parallel lines of red, white, blue and orange as people line the route. One unusual point about the Orange parade through Ardoyne on the Twelfth is that the witnesses of the spectacle and supporters of the parade are not able to stand on either side of the road for a distance of about 450 metres. As a consequence, the supporters of the parade from the southern side of Ardoyne are corralled at two exits off the roundabout - Twaddell Avenue and Woodvale Road.

The positioning of this group is very important as their presence and size has a direct effect on tensions during the parade. This was particularly notable during 2013, when tensions were particularly high given the flag protests by loyalists, which had caused civil disruption over the Christmas period before and resulted in the setting up of a loyalist protest camp at the top of Twaddell (Nolan et al. 2014). There was a heavy police presence, with police having been drafted in from England to boost the capacity of the PSNI. The number of supporters was much more than the previous year and the police moved the group to different locations behind the roundabout. Standing in the crowd, this adjustment of position had the effect of raising expectations that the parade was imminent, only for yet 
more waiting to follow. In the vacuum of communication, rumours were flying around about riots having broken out at the top of the parade. Such rumours were all the more wild and effective because of the fact that the supporters were unable to see the parade itself. The density of the crowd and the close cordon enforced by the police meant that a slightly claustrophobic atmosphere was evident.

It became increasingly important for the supporters to be visible and noticed. If the marchers were under fire further up the route, it was all the more important that they knew that a strong crowd of supporters were waiting for them. In this way, the supporters used their visibility to bolster the marchers' quest for recognition.

Another perspective on the role of supporters was gained for us the previous year, when we came down the route of the parade as part of the marching group itself. Hemmed into the road, lines of police either side, banners of Orange Lodges being held overhead - it was difficult as a marcher to get a clear glimpse of the protestors that were objecting the parade. Although the music of the bands had been silenced (as decided by the Parades Commission), what we could hear was the cheering and singing from the group of supporters waiting at the roundabout. The 'frisson of danger' that went with being part of the parade along a contested route and objected to by residents meant that the sense of celebration and triumph when welcomed by a crowd singing the famous Orange song 'The Sash' was enormous. ${ }^{6}$ The visibility of the supporters was, thus, directed not so much at the protestors, as one might expect, but at the marchers.

\section{Agitators: Exploiting visibility as control in order to show resistance}

Those involved in the negotiation and management of contentious events locally are usually people in positions of authority within their communities. This authority can derive either from their capacity of local residents, positions within traditional local institutions (churches, schools) or from their experience with political conflict (often such people are former combatants, political prisoners or paramilitaries). Yet, the very performance of contentious parades and protests represents not simply a testament to the authority of such figures but, increasingly, intra-communal challenges to

6 'The Sash' is a ballad commemorating the victory of King William III (known as William of Orange) in the Williamite-Jacobite War in Ireland in 1688-1691. 'The sash' refers to the regalia of the Orange Order, which is the fraternal institution established at the end of the eighteenth century to celebrate the victory of King William for Protestant ascendancy, particularly his victory at the decisive Battle of the Boyne on 12 July 1690. 
it. As such, contentious events have often been a visible manifestation of growing fragmentation within republicanism and challenges to the authority of Sinn Féin as the largest nationalist party.

It is therefore most accurate for us to report the activities of two types of protestors: the community residents' group (Crumlin Ardoyne Residents Association, CARA), which is loosely associated with Sinn Féin, and the hard-line group associated with dissident republicanism (Greater Ardoyne Residents Collective, GARC), which advocates more direct action to disrupt the parade. Whereas CARA is involved in behind-the-scenes negotiations with the police and those associated with the Orange parade, GARC criticizes this approach as too concessionary. The differences in approach were most starkly evident in 2009 when members of GARC sat on the Crumlin Road to block the route of the parade. Their forced removal by police officers generated the type of headlines and photographs that they had hoped for. This group recognizes that its members' visibility is a form of control by police and they seek to exploit this for their own political ends. Another act of resistance by GARC utilizing their members' visibility was holding its own parade whilst complying with the requirement to submit its intentions to the Parades Commission in advance. This allowed GARC a further means of exploiting visibility as control: it requested that its parade be on the Crumlin Road at exactly the same time as the returning Orange parade. This clearly set up a direct confrontation between the rights of both sides - not just on the road, but across the committee table of the Parades Commission, if not in their physical presence on the Crumlin Road at the same time.

For the most part, the tactics of GARC are to distract the police and supporters from the main legitimate protest by breaching the requirements of the Parades Commission vis-à-vis the use of space, particularly its ruling on where protestors should stand. By simply walking 20 metres away from the main protest towards the roundabout, GARC members immediately heighten their visibility. They are noticed not only by police but by journalists and by supporters of the parade itself.7 In this way, the 'visibility as control' being used by the Parades Commission is exploited ruthlessly to its full potential to 'agitate'. In 2011, when the GARC protestors attempted to move towards the roundabout, they were closely followed by police, journalists and human

7 We observed on several occasions how supporters of the parade took it upon themselves to draw the attention of the police to any potential breach of the Parades Commission's rulings by GARC. This is partly because the supporters' position, at the roundabout, allows easier view of potential 'breakaway' groups than the main body of protestors. In 2013 we witnessed an overenthusiastic group of supporters demand that the police question a young couple walking down the unapproved route beside the roundabout; they turned out to be bemused tourists. 
rights observers. The exclamation by one middle-aged woman from the breakaway group is telling: it was not an expression of defiance aimed at the police, but one of provocation aimed at their fellow republicans: 'Where are you, Sinn Féin?' The impression of resistance, the effect of agitation is where GARC seeks to distort the visibility of control.

\section{Protestors: Seeking to counter the marchers with their own quest for recognition}

Ironically, the visibility of the main protest group (CARA) risks being diminished by the activity of the agitators. We noted, when we were in the Gold Command Room in 2016, how the feed of the police helicopter over the site of the protest does not concentrate on CARA but on GARC. Whereas GARC uses space to full advantage (spreading out before the parade arrives, thinning out police lines by ensuring they are followed by police), CARA is much more contained. Their presence, immediately proximate to the parade, spread in a line just one-person deep, for a stretch of about 20 metres, is primarily to counter the marchers' quest for recognition with their own counter-quest. The protestors talk quietly among themselves and rarely address comments at the marchers (even when provoked). Instead, they communicate their message through the use of posters, knowing that this can project a message much more clearly to a much wider audience (through disseminating images on [social] media networks) than any chants or verbal exchanges. These posters have fairly consistent messages. It is noteworthy that in 2016 CARA held a large banner stating 'Resolution is possible'. The following year, they decided not to protest.

It is interesting now, after a long period of observation of this protest and interviews with the protestors, to see what effect their decision to become 'invisible' had on the contentious nature of the parade. After much behindthe-scenes negotiation in 2017, the Twaddell camp was finally dismantled. There was no official protest on the morning of the Twelfth, and the return parade complied with strict conditions and passed off peacefully. By refusing to stand protestors withdrew themselves as witnesses for the marchers' quest for recognition. In so doing, the parade returned to being primarily 'visibility as spectacle', with the principal audience being their own supporters.

\section{Police: Using visibility as control}

The final group of agents we consider in the management of this contentious event is that of the police. The police themselves are fully conscious that the performance of contentious events is the most immediate threat to their attempts to develop good relationships with local communities - particularly 
those in 'interface' areas. ${ }^{8} \mathrm{~A}$ police commander commented, for instance, that while promoting 'empathetic' and 'responsive' policing is both what the police aim to do and what 'interface' communities have come to expect from them, contentious events by their nature require the use of coercion, making it 'hard to convince people that you are there to police with the community. [...] So, when you're involved in that type of policing there's a risk that you continue to alienate people. 9 The complex maelstrom of power relationships involved in the negotiation, attempts at management and the policing of contentious events most directly thwart the development of community policing, based on stable and trusting community-police relationships locally and on police institutional legitimacy more broadly.

Our observations of the Twelfth Orange Order parade and the nationalist protests confirm that the PSNI does attempt to ensure that the visibility of the police is carefully choreographed so as to reduce tensions and the sense of surveillance and control that further exacerbates tensions in the local community. Small changes in the visibility of the police have been shown to make a big difference in defusing potential conflict. Such changes include: the clothing of the police (white shirt sleeves and soft caps rather than riot gear), the direction in which they face (i.e. not all towards the protestors, which gave the impression that they alone were the source of potential trouble), the number of police on the road (the vast majority are ensconced in Land Rovers adjacent to the route), and the speed with which they evacuate the area (as soon as the last marcher has crossed the other side of the roundabout, there is a line of police Land Rovers exiting the area at speed). Such efforts are positively commented on in our interviews, indicating that even the body positions of individual officers are both carefully watched and judged to have significance for defining who and what is seen as 'the problem' on the day. The shape and positioning of police lines and cordons are considered to display the police's degree of commitment to even-handedness and neutrality (Bryan 2006).

That said, over the past decade the use of cameras has also grown exponentially. There is the camera of the police helicopter overhead (so strong, we witnessed from the Gold Command Room, that it is possible to read the brand of a chocolate bar on the ground from 1,00o feet). There are also large

8 These are areas (usually working class) where Protestant and Catholic communities live side by side. In Belfast such areas have been the sites for a disproportionate amount of violence during 'the Troubles'; continue to witness regular outbreaks of sectarian disquiet; and to exhibit higher levels of social deprivation.

9 Interview with a district police commander, 21/09/2010. 
cameras facing in several different directions from tall poles on the top of an armoured police Land Rover, which is a very familiar vehicle in public order situations in Northern Ireland. In addition, individual police officers carry small handheld cameras which they clearly direct at certain groups. There are also CCTV cameras on lampposts and shop fronts and cameras in the hands of other subjects (marchers, supporters, protestors, journalists). Visibility as control is no longer exclusively in the hands of the police. With the increasing technologization of visibility as such, its use as control has become more subtle. Rather than keeping out of the eyeline of a particular officer, each individual marcher and protestor may be conscious that they are being watched and recorded, and thus their actions are potentially viewed by dozens if not hundreds of people. As it is, a contentious event such as this embodies an unusual melding of physical, territorial and temporal space together with a type of control that transcends the constraints of physical presence, territory and time. The critical point of commonality here is that of visibility. Any and all changes in the dynamics of visibility result in changes to the whole dynamic of the event.

\section{Conclusion}

It is appropriate to reflect at this point on the longitudinal form of qualitative research applied in this case. This was made possible by the uniquely cyclical (annual) rhythm and predictable spatial positioning of the events we study. As such, we were able to, and itself enabled us to pinpoint acts of visibility-production in the situational and sociopolitical dynamics of these events in Northern Ireland.

Interpreting parades and protests as primarily quests for visibility further enriches understandings of these events as performative struggles over territory, and as solidarity-boosting collective rituals. From a practical perspective, a focus on visibility helps develop a more thorough and detailed appreciation of the shifting dynamics of power relationships in their dependence on spatial, material, technological and performative means of production. It demonstrates that contentious events serve as direct stages for intra- (as well as inter-) communal power struggles (opposition to and contestation of political authority) and the crucial role that space and performativity play both as media and as resources of these power relations. The three models of visibility that Brighenti (2010c) speaks of - recognition, control and spectacle - are clearly not mutually exclusive. In our case study at every one moment of time the three were present. They also have 
particular potency in a 'post-conflict' context. We have shown here how in a sensitive and sometimes volatile environment, the use of visibility by different agents is a very useful tool for understanding why some actions have the effect of increasing conflict while others defuse it.

In our case study, we have witnessed the transition over time from a fairly violent and tense event to a fairly routine and mundane one. We do not assume that the problem of the contentious Orange parade through Ardoyne has been resolved. As a predictable event and a highly symbolic tradition, the parade will always be vulnerable to exploitation by those who wish to demonstrate resistance or to seek recognition. That said, it is notable that the contention on the day has been dramatically reduced simply by the tit-for-tat quest for visibility being made much more one-sided: if there are fewer witnesses, then the act immediately becomes less powerful or important. Moreover, being a witness also makes one a subject, that is, the attention of the gaze of others are on one. In realizing this and actively averting visibility, actors have the opportunity to regain the type of agency that they had feared was impossible under such police presence and cultural provocation.

On the one hand, therefore, this reveals the use of visibility as a major vehicle for the flux and flow of power relationships. In particular, it can help explain why events, interactions and social actors can be rendered either socially relevant or insignificant. From a conceptual point of view, on the other hand, our focus on parades and protests as contestation over visibility itself (rather than as struggles over territory), stresses an understanding of social territoriality that decouples it from physical space. This idea builds on Brighenti's suggestion that 'territory is better conceived as an act or practice rather than an object or physical space' (2010b: 53). What counts, therefore, is 'the relationships among people that are built through space and inscribed in it' (2010b: 55). As such, the contentious events that we study must be understood as acts of inscription etching territorial patterns of social and political relationships onto physical space.

\section{References}

Allen, John. 2003. Lost Geographies of Power. Oxford: Blackwell.

Allen, John. 2008. 'Pragmatism and Power, or the Power to Make a Difference in a Radically Contingent World', Geoforum 39(4): 1613-1624.

BBC. 2011. 'Belfast Riots: Appeals for Calm after Night of Violence', BBC.com, 12 July. http://www.bbc.co.uk/news/uk-northern-ireland-14130190. Accessed 12.06.19. 
Brighenti, Andrea Mubi. 2010a. 'Democracy and Its Visibilities', in Surveillance and Democracy, ed. Kevin. D. Haggerty and Minas Samatas, 51-68. London: Routledge. Brighenti, Andrea Mubi. 2010b. 'On Territorology: Towards a General Science of Territory', Theory, Culture \& Society 27(1): 52-72.

Brighenti, Andrea Mubi. 2010c. Visibility in Social Theory and Social Research. Basingstoke: Palgrave Macmillan.

Browne, Brendan. 2016. 'Choreographed Segregation: Irish Republican Commemoration of the 1916 Easter Rising in "Post Conflict" Belfast', Irish Political Studies 31(1):101-121. Bryan, Dominic. 2000. Orange Parades: The Politics of Ritual, Tradition and Control. London: Pluto Press.

Bryan, Dominic. 2006. 'The Anthropology of Ritual: Monitoring and Stewarding Demonstrations in Northern Ireland', Anthropology in Action 13(1): 22-32.

Cohen, Saul. 2007. 'Winning While Losing: The Apprentice Boys of Derry Walk Their Beat', Political Geography 26(8): 951-967.

Dovey, Kim. 2005. 'The Silent Complicity of Architecture', in Habitus: A Sense of Place, ed. Jean Hillier and Emma Rooksby, 283-296. Aldershot: Ashgate.

Durkheim, Émile. 2001. The Elementary Forms of Religious Life, trans. Carol Cosman. Oxford: Oxford University Press.

Gambetti, Zeynep. 2004. 'The Conflictual (Trans)formation of the Public Sphere in Urban Space: The Case of Diyarbakir', EUI Working Papers, RSCAS No. 2004/38. http://cadmus.eui.eu/bitstream/handle/1814/2780/04_38.pdf;sequence=1. Accessed 13.06.19.

Goffman, Erving. 2005. Interaction Ritual: Essays in Face-to-Face Behavior. New Brunswick, NJ: Aldine Transaction.

Hajer, Maarten A. 2005. 'Setting the Stage: A Dramaturgy of Policy Deliberation', Administration and Society 36(6): 624-647.

Hajer, Maarten A. 20o9. Authoritative Governance: Policy-making in the Age of Mediatization. Oxford: Oxford University Press.

Honneth, Axel. 1995. The Struggle for Recognition: The Moral Grammar of Social Conflicts. Cambridge: Polity Press.

Jarman, Neil. 1997. Material Conflicts: Parades and Visual Displays in Northern Ireland. Oxford: Berg.

Koster, Jan. 2003. 'Ritual Performance and the Politics of Identity: On the Functions and Uses of Ritual', Journal of Historical Pragmatics 4(2): 211-248.

Lukes, Steven. 1975. 'Political Ritual and Social Integration', Sociology 9: 289-308. McGarry, Aidan, Itir Erhart, Hande Eslen-Ziya, Olu Jenzen, and Umut Korkut. 2019. 'Introduction: The Aesthetics of Global Protest: Visual Culture and Communication', in The Aesthetics of Global Protest: Visual Culture and Communication, ed. Aidan McGarry, Itir Erhart, Hande Eslen-Ziya, Olu Jenzen, and Umut Korkut. Amsterdam: Amsterdam University Press. 
Nolan, Paul, Bryan Dominic, Clare Dwyer, Katy Hayward, Katy Radford, and Peter Shirlow. 2014. The Flag Dispute: Anatomy of a Protest. Belfast: Queen's University. https://pure.qub.ac.uk/ws/files/13748797/The_Flag_Dispute_report_PRINTED. pdf. Accessed 13.06.19.

Parkinson, John. 2012. Democracy and Public Space: The Physical Sites of Democratic Performance. Oxford: Oxford University Press.

Rose, Nikolas. 1999. Powers of Freedom: Reframing Political Thought. Cambridge: Cambridge University Press.

Ross, Marc Howard. 2007. Cultural Contestation in Ethnic Conflict. Cambridge: Cambridge University Press.

Walsh, Dawn. 2015. 'Northern Ireland and the Independent Parades Commission: Delegation and Legitimacy', Irish Political Studies 30(1): 20-40.

\section{About the Authors}

Katy Hayward is Reader in Sociology, and a Fellow of the Senator George J. Mitchell Institute for Global Peace, Security and Justice at Queen's University Belfast. A political sociologist, her research expertise centres on processes of conflict and conflict transformation on the island of Ireland. Among her recent publications are the co-edited book Dynamics of Political Change in Ireland (2017) and a co-edited (with Niall Ó Dochartaigh) special issue of Nationalism and Ethnic Politics on the subject of 'Nationalism and Organized Violence' (2013).

Milena Komarova is a Research Officer at the Centre for Cross Border Studies, Armagh, and a Visiting Research Fellow at the Senator George J. Mitchell Institute for Global Peace, Security and Justice, Queen's University Belfast. She holds a PhD in Sociology from Queen's University Belfast (2008). Her research work traverses the fields of conflict transformation, border and urban studies, including the interplay between conflict and everyday life practices and spaces in cities, and the effects of Brexit on the UK-Ireland border. Among her more recent publications is "You Have No Reason to Access": Visibility and Movement in Contested Urban Space', in Ethnographies of Movement, Sociality and Space. Place-making in the New Northern Ireland, ed. M. Komarova and M. Svašek (Berghahn, 2018). 
